\title{
Biennial Overview of AMS Honors
}

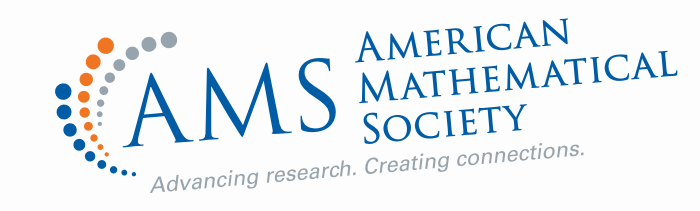

Every two years, the Notices, as the Society's journal of record, publishes an overview of AMS honors. In this section, we list the special lishes an overview of AMS honors. In this sective brief descriptions of
lectures, prizes, awards, and fellowships; give
each; and provide links for further information, including past recipients and lecturers.

The Society governance consists of the Officers (President, three Vice Presidents, Secretary, four Associate Secretaries, Treasurer, and Associate Treasurer), the Council, Executive Committee of the Council, and Board of Trustees. You may find ince, which includes links to governance at www.ams.org/g the AMS: A Semicentennial History books that chronicle the hist Society, 1888-1938, by Raymond Clare of the American Mathematica Sociend Fifty Years, American Mathematical Archibald, and History of therett Pitcher. We begin with a list of past presidents, treasurers, and secretaries.

Cace D. darage

Carla D. Savage, AMS Secretary 


\section{Presidents}

2019-2020 Jill C. Pipher

2017-2018 Kenneth A. Ribet

2015-2016 Robert L. Bryant

2013-2014 David A. Vogan, Jr.

2011-2012 Eric M. Friedlander

2009-2010 George E. Andrews

2007-2008 James G. Glimm

2005-2006 James G. Arthur

2003-2004 David Eisenbud

2001-2002 Hyman Bass

1999-2000 Felix E. Browder

1997-1998 Arthur M. Jaffe

1995-1996

1993-1994

1991-1992

1989-1990

1987-1988

1985-1986

1983-1984

1981-1982

1979-1980

1977-1978

1975-1976

1973-1974

1971-1972

1969-1970

1967-1968

1965-1966

1963-1964

1961-1962

1959-1960

1957-1958

1955-1956

1953-1954

1951-1952
Cathleen Synge Morawetz

Ronald L. Graham

Michael Artin

William Browder

George Daniel Mostow

Irving Kaplansky

Julia Bowman Robinson

Andrew Mattel Gleason

Peter David Lax

R H Bing

Lipman Bers

Saunders Mac Lane

Nathan Jacobson

Oscar Zariski

Charles Bradfield

Morrey, Jr.

Abraham Adrian Albert

Joseph Leo Doob

Deane Montgomery

Edward James McShane

Richard Dagobert Brauer

Raymond Louis Wilder

Gordon Thomas

Whyburn

John von Neumann
1949-1950

1947-1948

1945-1946

1943-1944

1941-1942

1939-1940

$1937-1938$

1935-1936

1933-1934

1931-1932

1929-1930

1927-1928

1925-1926

1923-1924

1921-1922

1919-1920

1917-1918

1915-1916

1913-1914

1911-1912

1909-1910

1907-1908

1905-1906

1903-1904

1901-1902

1899-1900

1897-1898

1895-1896

1891-1894

1888-1890
Joseph Leonard Walsh

Einar Hille

Theophil Henry

Hildebrandt

Marshall Harvey Stone

Harold Calvin

Marston Morse

Griffith Conrad Evans

Robert Lee Moore

Solomon Lefschetz

Arthur Byron Coble

Luther Pfahler Eisenhart

Earle Raymond Hendrick

Virgil Snyder

George David Birkhoff

Oswald Veblen

Gilbert Ames Bliss

Frank Morley

Leonard Eugene Dickson

Ernest William Brown

Edward Burr Van Vleck

Henry Burchard Fine

Maxime Bôcher

Henry Seely White

William Fogg Osgood

Thomas Scott Fiske

Eliakim Hastings Moore

Robert Simpson

Woodward

Simon Newcomb

George William Hill

John Emory McClintock

John Howard Van

Amringe

\section{Treasurers}

$\begin{array}{ll}2011-2021 & \text { Jane M. Hawkins } \\ 1999-2010 & \text { John M. Franks } \\ 1974-1998 & \text { Franklin P. Peterson } \\ 1965-1973 & \text { W. T. Martin } \\ 1949-1964 & \text { A. E. Meder, Jr. } \\ 1938-1948 & \text { B. P. Gill } \\ 1937 & \text { P. A. Smith } \\ 1930-1936 & \text { G. W. Mullins } \\ 1921-1929 & \text { W. B. Fite } \\ 1908-1920 & \text { J. H. Tanner } \\ 1900-1907 & \text { W. S. Dennett } \\ 1897-1899 & \text { Harold Jacoby } \\ 1895,1896 & \text { R. S. Woodward } \\ 1892-1894 & \text { Harold Jacoby } \\ 1890,1891 & \text { T. S. Fiske }\end{array}$

\section{Secretaries}

2013-2021

1999-2012

1989-1998

1967-1988

1957-1966

1951-1956

1941-1950

1921-1940

$1896-1920$

1888-1895

Carla D. Savage

Robert J. Daverman

Robert M. Fossum

Everett Pitcher

J. W. Green

E. G. Begle

J. R. Kline

R. G. D. Richardson

F. N. Cole

T. S. Fiske
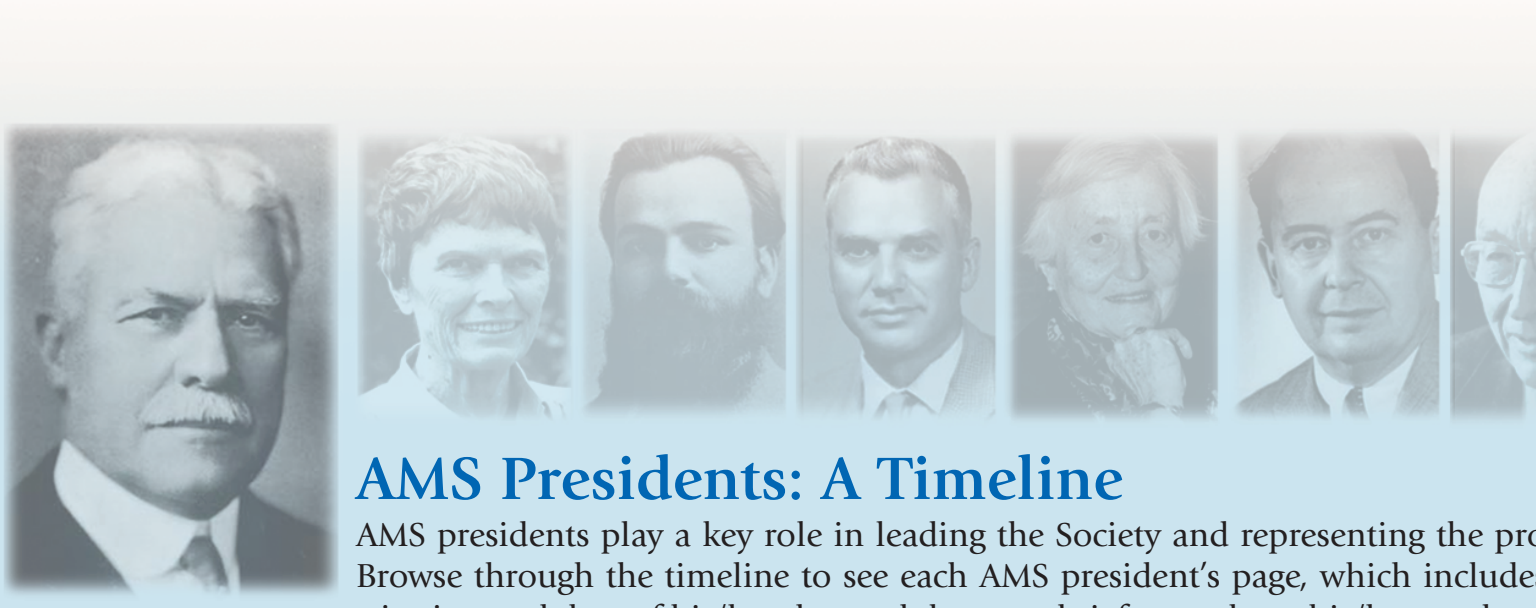

\section{AMS Presidents: A Timeline}

AMS presidents play a key role in leading the Society and representing the profession. Browse through the timeline to see each AMS president's page, which includes the institution and date of his/her doctoral degree, a brief note about his/her academic career and honors, and links to more extensive biographical information.

www.ams.org/presidents 
In addition to the Invited Addresses at the Joint Mathematics Meetings and at the eight Sectional Meetings each year, the Society sponsors or CO-sponsors several special lectures. In 2020, the first Maryam Mirzakhani Lecture will be presented at the Joint Mathematics Meetings.

\section{AMS Special Lectures}

\section{Colloquium Lectures}

www.ams.org/meet-colloquium-lect

The Colloquium Lectures have a long and prestigious history. Maxime Bôcher and James Pierpont delivered the first sets of lectures in 1896. They continue today as a highlight of the Joint Mathematics Meetings.

Josiah Willard Gibbs Lectures

www.ams.org/meet-gibbs-lect

These invited lectures are of popular nature, directed at those who are not professional mathematicians. The Society established the Gibbs Lectures in 1923.

NEW! The Maryam Mirzakhani Lectures

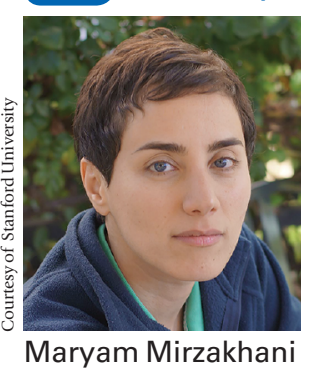

www.ams.org/meet-mirzakhani-lect The AMS Council established this Lecture in 2018 to honor Maryam Mirzakhani (1977-2017), the first woman and the first Iranian to win a Fields Medal. The inaugural Mirzakhani Lecture will be delivered by Tatiana Toro at the 2020 Joint Mathematics Meetings in Denver, Colorado.

\section{Erdős Memorial Lectures}

www.ams.org/meet-erdos-lect

The Erdős Memorial Lecture is an invited address given annually since 1999 at one of the Society's eight sectional meetings. The Lecture is named for the prolific mathematician Paul Erdős (1913-1996).

\section{Einstein Public Lectures in Mathematics}

www.ams.org/meet-einstein-lect

The Einstein Lectures, created by the AMS in 2005 to celebrate the one-hundredth anniversary of Einstein's annus mirabilis, are given annually at one of the Sectional Meetings.

\section{Arnold Ross Lectures} www.ams.org/ross-lectures

Created by the AMS at the encouragement of Paul Sally, these annual lectures are aimed at talented high school mathematics students to stimulate their interest in mathematics beyond the traditional classroom.

\section{Joint Lectures}

\section{AMS-MAA-SIAM Gerald and Judith Porter Lectures} www.ams.org/porter-lect

The Porter Lecture on a mathematical topic accessible to the broader community is given each year at the Joint Mathematics Meetings.

\section{AWM-AMS Noether Lectures}

www.awm-math.org/noether-lectures

The Noether Lecture, given each year at the Joint Mathematics Meetings, honors women who have made fundamental and sustained contributions to the mathematical sciences.

AMS-MAA Joint Lectures at MathFests

www.ams.org/ams-mathfest

These joint addresses, delivered annually at MathFest, are historical or expository in character.

\section{AMS-MAA Joint Lectures at the JMM}

www.jointmathematicsmeetings.org/2217_invited.html The AMS and MAA co-sponsor two lectures each year at the JMM. These are among the most popular events at the Meetings.

\section{AMS-Sponsored Lectures at SIAM Meetings} www.ams.org/ams-siam-lect

AMS selects a lecturer to deliver an address at the SIAM Annual Meeting.

The AMS-NZMS Maclaurin Lectureship

www.ams.org/maclaurin-lectures

This lectureship was a six-year reciprocal exchange between the New Zealand Mathematical Society and American Mathematical Society.

The Current Events Bulletin www.ams.org/current-events-bulletin

Organized by David Eisenbud, this JMM event features speakers surveying some of the most interesting current developments in mathematics, pure and applied. 


\section{AMS Prizes}

AMS Prizes recognize outstanding achievement in mathematics, exceptional public service in support of research and education in the mathematical sciences, and significant contributions to the public understanding of mathematics. The Society added a new prize in 2019: the Mary P. Dolciani Prize for Excellence in Research. The prizes below are awarded at the Prize Ceremony at the Joint Mathematics Meetings.

Leroy P. Steele Prizes

www.ams.org/steele-prize

- Lifetime Achievement

- Mathematical Exposition

- Seminal Contribution to Research

Bôcher Memorial Prize

www.ams.org/bocher-prize

For a notable paper in analysis

Frank Nelson Cole Prize in Algebra www.ams.org/cole-prize-algebra

For a notable paper in algebra

Levi L. Conant Prize

www.ams.org/conant-prize

For an expository paper published in either the Notices of the AMS or the Bulletin of the AMS

NEW!

The AMS Mary P. Dolciani Prize

for Excellence in Research

www.ams.org/dolciani-prize

Recognizes a mathematician from a department that does not grant a PhD who has an active research program in mathematics and distinguished record of scholarship

Ruth Lyttle Satter Prize in Mathematics

www.ams.org/satter-prize

For an outstanding contribution to mathematics research by a woman

Leonard Eisenbud Prize for Mathematics and Physics www.ams.org/eisenbud-prize

For work that brings mathematics and physics closer together

E. H. Moore Research Article Prize www.ams.org/moore-prize

For a research article appearing in one of the AMS primary research journals
David P. Robbins Prize

www.ams.org/robbins-prize

For a paper on novel research in algebra, combinatorics, or discrete mathematics

Bertrand Russell Prize of the AMS

www.ams.org/russell-prize

For research or service contributions of mathematicians or related professionals to promoting good in the world, recognizing the various ways that mathematics furthers human values

Chevalley Prize in Lie Theory

www.ams.org/chevalley-prize

For notable work in Lie theory

Frank Nelson Cole Prize in Number Theory www.ams.org/cole-prize-number-theory

For a notable paper in number theory

Joseph L. Doob Prize

www.ams.org/doob-prize

For a single, relatively recent, outstanding research book

Ulf Grenander Prize in Stochastic Theory and Modeling

www.ams.org/grenander-prize

For theoretical and applied contributions in stochastic theory and modeling

Albert Leon Whiteman Memorial Prize www.ams.org/whiteman-prize

For notable exposition and exceptional scholarship in the history of mathematics

Oswald Veblen Prize in Geometry www.ams.org/veblen-prize

For a notable research memoir in geometry or topology

Award for Distinguished Public Service

www.ams.org/public-service-award

For a research mathematician who has made a distinguished contribution to the mathematics profession 


\section{AMS Awards and Fellowships}

The Joan and Joseph Birman Fellowship

for Women Scholars

www.ams.org/Birman-fellow

Seeks to address the paucity of women at the highest levels of research in mathematics by giving exceptionally talented women extra research support during their mid-career years.

\section{Centennial Fellowship}

www.ams.org/centennial-fellow

For outstanding mathematicians to help further their careers in research, with a focus on candidates who have not had extensive fellowship support in the past.

AMS Congressional Fellowship www.ams.org/ams-aaas-congressional-fellowship

Selected Fellows spend a year working for a member of Congress or a congressional committee as a special legislative assistant in policy areas requiring scientific and technical input.

\section{AMS Mass Media Fellowship} www.ams.org/massmediafellow

In affiliation with the American Association for the Advancement of Science (AAAS), the AMS sponsors ten-week fellowships for graduate students in mathematics to work full time over the summer as reporters, researchers, and production assistants in US mass media organizations-radio and TV stations, newspapers, and magazines.

Waldemar J.Trjitzinsky Memorial Awards www.ams.org/trjitzinsky-award

Provides assistance to students who have declared a major in mathematics at a college or university that is an institutional AMS member.

Award for Impact on the Teaching

and Learning of Mathematics

www.ams.org/impact

For mathematicians who have made significant contributions of lasting value to mathematics education.

\section{Karl Menger Memorial Award}

www.ams.org/menger-award

For mathematically oriented projects presented at the International Science and Engineering Fair.

Mathematics Programs that Make a Difference Award www.ams.org/make-a-diff-award

Aims to bring more persons from underrepresented backgrounds into some portion of the pipeline beginning at the undergraduate level and leading to advanced degrees in mathematics and professional success, or retain them once in the pipeline.

Exemplary Program or Achievement in Mathematics Department Award www.ams.org/department-award

For a department which has distinguished itself by undertaking an unusual or particularly effective program of value to the mathematics community.

Epsilon Awards for Young Scholars Programs www.ams.org/epsilon-award

Supports existing summer programs for mathematically talented high school students.

Fellows of the American Mathematical Society www.ams.org/ams-fellows

Recognizes members who have made outstanding contributions to the creation, exposition, advancement, and utilization of mathematics.

\section{Joint Prizes and Awards}

George David Birkhoff Prize in Applied Mathematics www.ams.org/birkhoff-prize

Given jointly with the Society for Industrial and Applied Mathematics for an outstanding contribution to applied mathematics in the highest and broadest sense.

Norbert Wiener Prize in Applied Mathematics

www.ams.org/wiener-prize

Given jointly with the Society for Industrial and Applied Mathematics for an outstanding contribution to applied mathematics in the highest and broadest sense.

Frank and Brennie Morgan Prize

for Outstanding Research in Mathematics

by an Undergraduate Student

www.ams.org/morgan-prize

Given jointly with the Mathematical Association of America and the Society for Industrial and Applied Mathematics for outstanding research in mathematics.

Delbert Ray Fulkerson Prize

www.ams.org/fulkerson-prize

Given jointly with the Mathematical Optimization Society for outstanding papers in the area of discrete mathematics. 
AMS/ASA/ACM/IMS/MAA/SIAM

Joint Science \& Technology Fellowships

With support from the Alfred P. Sloan Foundation, this joint fellowship places PhD mathematicians and other data scientists in a federal agency or on the staff of a Congress member or on a congressional committee for one year.

JPBM Communications Award www.ams.org/jpbm-comm-award

Given jointly with the Mathematical Association of America, the Society for Industrial and Applied Mathematics, and the American Statistical Association, to reward and encourage communicators who, on a sustained basis, bring mathematical ideas and information to non-mathematical audiences.

Mathematical Art Exhibition Award

www.ams.org/art-exhibit-prize

Given jointly with the Mathematical Association of America for aesthetically pleasing works that combine mathematics and art.

\section{Other Prizes and Awards}

NEW! The Maryam Mirzakhani Prize in Mathematics (formerly The National Academy of Sciences Award in Mathematics)

Funding is currently being sought by the NAS to endow this award. The inaugural Mirzakhani Prize is scheduled for presentation in 2020. It will be awarded biennially for exceptional contributions to the mathematical sciences by a mid-career mathematician.

www.ams.org/nas-award

The Award for Outstanding Pi Mu Epsilon Student Paper Presentation, made by the National Honorary Mathematics Society.

www.ams.org/pme-award

These two awards have not been given in recent years:

The Public Policy Award was established in 2007 by the AMS to recognize a public figure for sustained and exceptional contributions to public policies that foster support for research, education, and innovation.

www.ams.org/profession/prizes-awards/ams-awards /public-policy-award

The Public Service Citation was created to provide encouragement and recognition for contributions to public service activities in support of mathematics.

www.ams.org/public-service-citation
The Beal Prize, funded by D. Andrew Beal, is awarded for either a proof or a counterexample of the Beal Conjecture which is published in a refereed and respected mathematics journal.

www.ams.org/beal-prize

The Stefan Bergman Prize is awarded by the Bergman Trust in honor of his research in several complex variables, as well as the Bergman projection and the Bergman kernel function.

www.ams.org/bergman-prize

The Fredkin Foundation asked the AMS to take over administration of its Fredkin Foundation prizes in Automatic Theorem Proving in the mid-1980s. This prize is no longer awarded.

www.ams.org/atp-prizes

The Leonard M. and Eleanor B. Blumenthal Award for the Advancement of Research in Pure Mathematics This prize was discontinued by the trust.

www.ams.org/blumenthal-award 